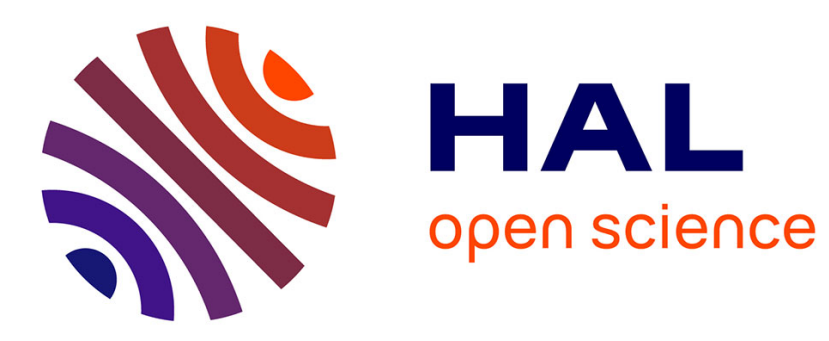

\title{
Hetero-Bimetallic Effect as a Route to Access Multinuclear Complexes
}

Zhongrui Chen, Gabriel Canard, Denis Jacquemin, Christophe Bucher, Michel Giorgi, Olivier Siri

\section{- To cite this version:}

Zhongrui Chen, Gabriel Canard, Denis Jacquemin, Christophe Bucher, Michel Giorgi, et al.. HeteroBimetallic Effect as a Route to Access Multinuclear Complexes. Inorganic Chemistry, 2018, 57 (20), pp.12536-12542. 10.1021/acs.inorgchem.8b01466 . hal-01891114

\section{HAL Id: hal-01891114 https://hal.science/hal-01891114}

Submitted on 31 Jan 2020

HAL is a multi-disciplinary open access archive for the deposit and dissemination of scientific research documents, whether they are published or not. The documents may come from teaching and research institutions in France or abroad, or from public or private research centers.
L'archive ouverte pluridisciplinaire HAL, est destinée au dépôt et à la diffusion de documents scientifiques de niveau recherche, publiés ou non, émanant des établissements d'enseignement et de recherche français ou étrangers, des laboratoires publics ou privés. 


\title{
Heterobimetallic effect as a new route to access multinuclear com- plexes
}

\author{
Zhongrui Chen, ${ }^{\dagger}$ Gabriel Canard, ${ }^{\dagger}$ Denis Jacquemin, ${ }^{*}$ Christophe Bucher, ${ }^{\S}$ Michel Giorgi ${ }^{\perp}$ and Olivier \\ Siri*i \\ ${ }^{\dagger}$ Aix Marseille Université, CNRS UMR 7325, CINaM, Campus de Luminy, case 913, 13288 Marseille cedex 09 (France) \\ * CEISAM UMR CNRS 6230, Université de Nantes, 2 rue de la Houssinière, BP 92208, 44322 Nantes Cedex 3 (France) \\ ${ }^{\S}$ Laboratoire de Chimie UMR 5182, CNRS - Univ. Lyon, ENS de Lyon, Univ. Claude Bernard Lyon 1, Lyon (France) \\ $\perp$ Aix Marseille Univ, CNRS, Centrale Marseille, FSCM, Marseille (France)
}

\begin{abstract}
We report the synthesis of a key mononuclear intermediate complex based on a quinoid ligand, and its further metalation to afford the corresponding heterobimetallic compound that revealed unique properties. An unprecedented heterobimetallic effect in coordination chemistry could be indeed observed and exploited to prepare, through selective ligand exchange, a tetranuclear complex (Pd-Ni-Ni-Pd) absorbing light up to the far-red region. Most importantly, we describe here to the best of our knowledge the first use of bischelating ligand for ligand exchange and this approach can be considered as a new route for incorporating planar units to access multi-heteronuclear complexes. The origin of this specific ligand exchange as well as of the nature of the electronic excited-states of the relevant structures have been investigated by first-principle calculations.
\end{abstract}

\section{INTRODUCTION}

Quinones belong to one of the most important classes of $\pi$ - conjugated molecules with applications covering a broad spectrum ranging from chemistry to materials science, physics to biology, and engineering to medicine. ${ }^{1}$ Quinones have attracted considerable interest in coordination chemistry because their $\pi^{*}$-orbitals can mix extensively with the valence d-orbitals of a metal center, allowing a full electron delocalization over both metal and ligand. ${ }^{2}$ As a consequence, remarkable properties emerged especially for complexes based on bis-chelating quinoidal ligands which could be used in catalysis, molecular electronics, magnetism or optics. ${ }^{3}$ The classical bis-chelating ligand in quinoid chemistry is the widely used 2,5-dihydroxy-1,4-benzoquinone 1 that can bind one, two or more metal centers. ${ }^{4}$ Noteworthy, although 1 is probably the most used quinoid ligand (more than 200 complexes have been reported), there are currently no record on heteronuclear complexes, most probably due to the high reactivity of both chelating sites.

The nitrogenated analogues $\mathbf{2}$ are in the limelight of coordination chemistry because of (i) the presence of N-substituents that can be tuned almost at will ${ }^{5}$, and (ii) the easy introduction of metal centers to form mono- ${ }^{6}$ and dinuclear complexes. ${ }^{3}$ These latter compounds (3) have been shown to be particularly useful in magnetism $(\mathrm{M}=\mathrm{Cu}, \mathrm{Fe}, \mathrm{Cr}, \mathrm{Mn}, \mathrm{Co}){ }^{7}$ catalysis $(\mathrm{M}=\mathrm{Ni}){ }^{8}$ polymer $(\mathrm{M}=$ $\mathrm{Na}){ }^{9}$ electromism $(\mathrm{M}=\mathrm{Pt})^{10}$ and optics $(\mathrm{M}=\mathrm{Ir}) .^{11}$ The great potential of homodinuclear complexes $(3)$ led us to investigate strategies which could provide access to the as yet unknown heterometallic analogues $\mathbf{4}$, featuring two different metal centers. We reasoned that the persistent failure to access such heterobimetallic species could arise from the poor stability of the mononuclear complexes reported so far. To address this issue, we propose here a stepwise approach based on the synthesis of square planar $\mathrm{d}^{8}$ metal mononuclear complexes enabling to maximize the electronic delocalization over the whole molecule, and consequently their stability. 

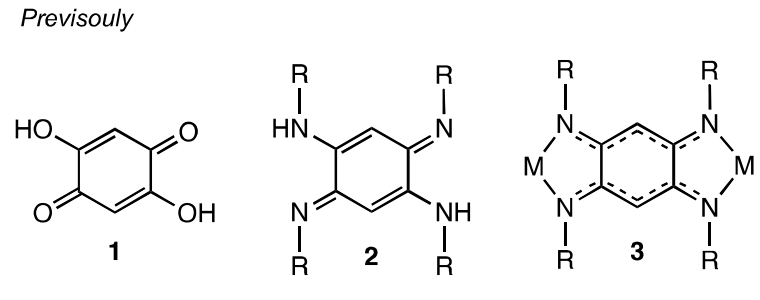

This work

As a preliminary step, we have focused on strategies allowing to produce multinuclear complexes by selective ligand exchanges since these reactions are metal-dependent and favored or unfavored depending on the affinity of the ligand. Interestingly, ligand substitutions in planar nickel(II) complexes have been extensively investigated for monodentate ligands, ${ }^{12}$ but never with bischelating motifs such as 2 .

In the present work, we report three major advances in coordination chemistry: (i) the synthesis of an unknown square planar mononuclear complex based on $\mathrm{N}_{4}$-type ligand 2, (ii) the complexation of two different metal center to afford the first heterobimetallic complex in quinonediimine chemistry, and (iii) a remarkable heterobimetallic effect that could be exploited to achieve a regioselective synthesis of coordination oligomers, one metal center being used as a reactive site (Ni) while the second one only plays the role of stopper (Pd). This latter process involves the incorporation, through selective exchange, of an exogenic ditopic binding moieties to yield a multinuclear complex (Pd-Ni-Ni-Pd) that presents a pronounced far-red absorption. Such straightforward exchange reactions have thus been implemented to achieve control over the length of metal-ligand oligomers involving the quinoid ligand 2 . The electronic effects of the metal ligation and the ligand exchange have been investigated by absorption spectroscopy and rationalized by ab inito calculations.

\section{RESULTS AND DISCUSSION}

The synthesis of square planar mononuclear complexes was first envisaged by reacting a stoichiometric amount of ligand $\mathbf{2}(\mathrm{R}=$ $\mathrm{nBu}$ ) and $\mathrm{M}(\mathrm{acac})_{2}$ (in THF for $\mathrm{M}=\mathrm{Ni}$ or dioxane for $\mathrm{M}=\mathrm{Pd}$ ). Unfortunately, this reaction did not afford the expected complex 5 but the dinuclear species $\mathbf{6 a}$ and $\mathbf{6 b}$ (Scheme 1). Selective formation of these complexes can be explained by an allosteric effect implying that metalation of the first chelating site enhances the metal-binding ability of the second site. In other words, $\mathbf{5}$ can be seen as an "activated" intermediate featuring improved metal-binding properties. The homodinuclear species $6 \mathbf{6}$ and $\mathbf{6 b}$ could be obtained in much better yields ( 72 and $70 \%$ respectively) from 2 when using two molar equivalents of M(acac). Their stability could be established both at the solid-state and in solution, even in the presence of an excess of 2 (Scheme 1).

\section{Scheme 1. Synthesis and reactivity of homodinuclear complexes 6a-b}

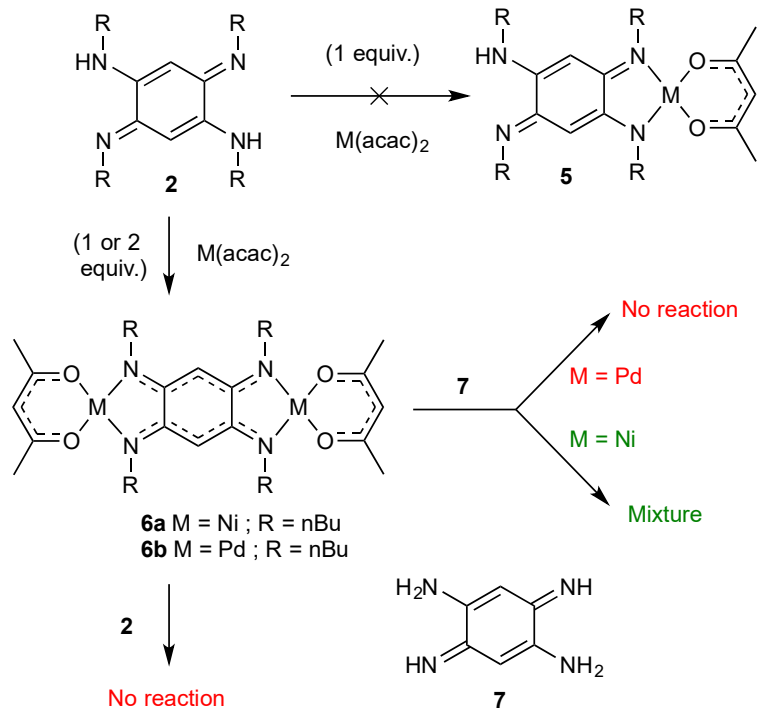


Remarkably, introduction of unsubstituted ligand 7 to a solution of $6 \mathbf{a}$ and $\mathbf{6 b}$ (up to $70^{\circ} \mathrm{C}$ ) revealed a drastic difference in reactivity depending on the metal centers. If an inseparable mixture of oligomers could be observed from $\mathbf{6 a}(\mathrm{M}=\mathrm{Ni})$, no reaction could be observed upon the same conditions from $\mathbf{6 b}$, evidencing both the crucial role of the metal and the impact of using an unhindered ligand 7 instead of $\mathbf{2}$. This observation can be explained by ligand substitution often encountered on planar nickel(II) complexes that undergo exchange ligand reactions. ${ }^{13}$ These results prompted us to devise synthetic strategies providing access to the heterobinuclear analogue 9 wherein: (i) the $\mathrm{Ni}$ (II) site could be available for ligand exchange, and (ii) the Pd(II) center could behave as a "stopper» preventing the formation of oligomers on this side. To address the above-mentioned allosteric effect, the metalation reaction was conducted in the presence of an acid used to annihilate the reactivity of the "metal free » binding site by selective protonation of one nitrogen atom. Thus, the free ligand $2(\mathrm{R}=n-\mathrm{Bu})$ was thus reacted with 1 equiv. of $\operatorname{Pd}(\mathrm{acac})_{2}$ and 1 molar equiv. of $\mathrm{HBF}_{4}$ in 1,4-dioxane to afford the corresponding mononuclear complex 8 as a dark powder in $81 \%$ yield (Scheme 2).

\section{Scheme 2. Stepwise synthesis of mono- (8), heterodi- $(9)$ and heterotetranuclear (10) complexes}
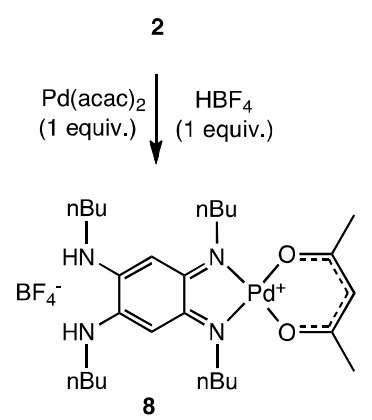

$$
\begin{gathered}
M(\mathrm{acac})_{2} \\
(1 \text { equiv. })
\end{gathered}
$$

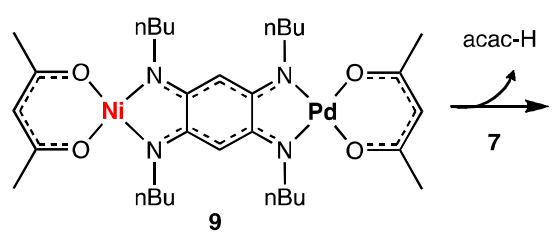

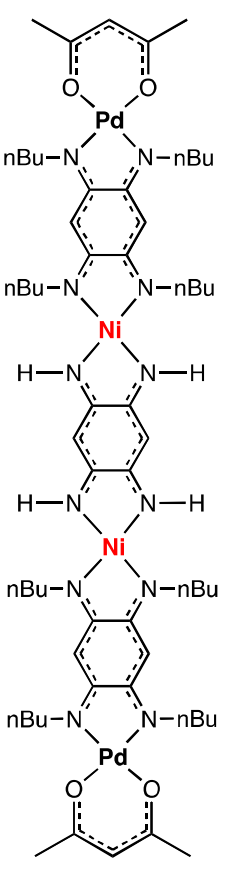

10

$\mathrm{X}$-ray diffraction analysis of complex 8 indicates the mono-metallation of the ligand and the presence of $\mathrm{BF}_{4}$ anion to balance the monocationic charge on the palladium center (see Figure 1 for 8). Close examination of the bond distances within the N(1)-C(1)$\mathrm{C}(2)-\mathrm{C}(3)-\mathrm{N}(3)$ and $\mathrm{N}(4)-\mathrm{C}(4)-\mathrm{C}(5)-\mathrm{C}(6)-\mathrm{N}(2)$ moieties of 8 revealed an alternating succession of single and double bonds and the presence of two imine functions in ortho position [C(1)-N(1) and $\mathrm{C}(6)-\mathrm{N}(2)]$, whereas the $\mathrm{C}(1)-\mathrm{C}(6)$ and $\mathrm{C}(3)-\mathrm{C}(4)$ are single bonds with respective distances of 1.502(4) and 1.493(4) $\AA$, highlighting the lack of conjugation between the two halves of the molecule. These data thus reveal that coordination of a metal center comes along with a para $\rightarrow$ ortho isomerization of the ligand ${ }^{6}$ which provides a square planar environment around the metal center, hitherto unknown for mononuclear complexes based on 2.

Next, 8 was reacted with an excess of $\mathrm{Ni}(\mathrm{acac})_{2}$ in $\mathrm{MeOH}$ at $60{ }^{\circ} \mathrm{C}$. The obtained precipitate was isolated by filtration to afford a brown powder identified as being the targeted heteronuclear complex 9 (37\% yield). In contrast to 8, X-ray diffraction study on single crystals of 9 revealed an extensive $\pi$-electronic delocalization (uniform bond lengths over the whole structure) whereas the lack of significant conjugation between the two $6 \pi$-subsystems was maintained, as already observed for homobimetallic complexes such as $\mathbf{6 a}$ and $\mathbf{6 b}$ and related dinickel complexes. ${ }^{8}$ The presence of the two different metals (Ni and Pd) was clearly established (by comparison with the X-ray data of $\mathbf{6 a}$ and $\mathbf{6 b}$, see SI), the metal centers and the ligand being quasi in the same molecular plane. 

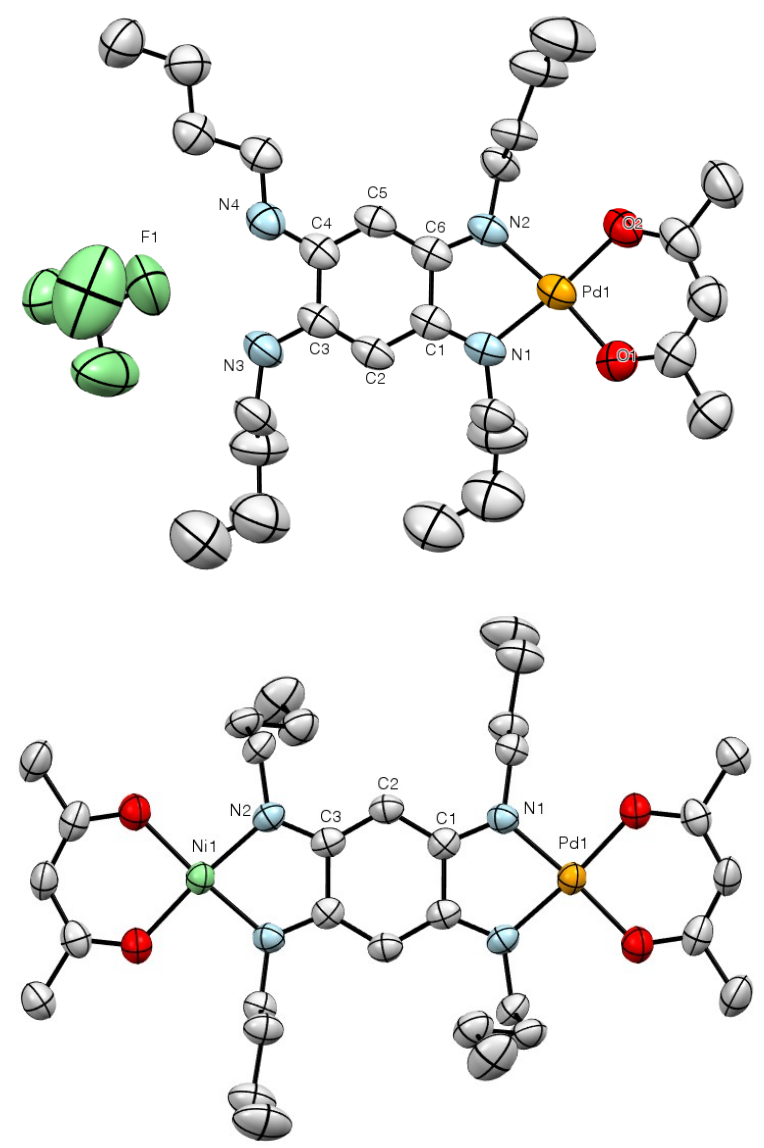

Figure 1. ORTEP views of 8 and 9 ( $\mathrm{H}$ atoms are omitted for clarity).

Interestingly, comparative NMR studies carried out on $\mathbf{6 a}, \mathbf{6 b}$ and 9 revealed that the heterobimetallic complex (9) exhibits key distinctive features of both homobimetallic reference compounds ( $6 \mathbf{a}$ and $\mathbf{6 b})$, as displayed for instance by the resonances of the N$\mathrm{CH}_{2}$ and $\mathrm{H}_{1}$ protons (Figure 2). Similar conclusions can be drawn from electrochemical data recorded in DCM on platinum electrodes. Each compounds exhibit two fully irreversible oxidation waves whose characteristic peak potential values are shifted upon replacing nickel with palladium $\left(E_{\mathrm{pal}}[\mathbf{6} \mathbf{a}]<E_{\mathrm{pal}}[\mathbf{6 b}]\right)$. As revealed by NMR, the CV curve of the mixed compound $\mathbf{9}$ can be seen as the sum of the signatures of $\mathbf{6 a}$ and $\mathbf{6 b}$ with $E_{\mathrm{pa} 1}[9] \approx E_{\mathrm{pa} 1}[\mathbf{6 a}]$ and $E_{\mathrm{pa} 2}[9] \approx E_{\mathrm{pa} 1}[\mathbf{6 b}]$ (see the SI). The potential values collected for all the complexes (see SI, Table S3) can be used to provide hints about the location of electron transfer. The first oxidation potential ( $E_{\mathrm{p}} \sim 0.5 \mathrm{~V}$ vs. SCE in all cases) collected for all the dinuclear species $\mathbf{6 a}, \mathbf{6} \mathbf{b}$ and $\mathbf{9}$ is for instance consistent with a ligandcentered oxidation process. This conclusion is obviously supported by the fact that the oxidation potential is poorly influenced by the metals complexed on both sides. In addition, metal centers in most Pd(II) and Ni(II) complexes are usually not oxidized at such low potential values (Pd(III) and $\mathrm{Ni}(\mathrm{III})$ complexes are quite rare and these oxidation states are difficult to stabilize). Such preliminary analysis can unfortunately only be carried out with the first oxidation processes due to the existence of chemical steps coupled to the electron transfer (EC type of mechanism). With respect to reduction, the same reasoning can be used to attribute the waves observed at similar potential values in DMF for $\mathbf{6 a}, \mathbf{6 b}$ and $\mathbf{9}$. Here again the limited influence of the metal centers strongly support the conclusion that reduction occurs on the ligand rather than on the metal.

Next, we were keen to exploit the heterobimetallic nature of $\mathbf{9}$ in which the Ni center should be reactive with respect to ligand exchange reactions whereas the Pd metal should be inert. To this end, complex $\mathbf{9}$ was reacted with the unsubstituted and bischelating ligand 7 ( 1 molar equiv.) in THF at room temperature. After 3 days, the tetranuclear complex $\mathbf{1 0}$ was isolated as a dark blue powder in $46 \%$ yield. This molecule is stable in solution under air and moisture in neutral or basic conditions, but appeared sensitive to acidic medium in solution (even in $\mathrm{CHCl}_{3}$ after several hours). Complex $\mathbf{1 0}$ was fully identified using NMR spectroscopy, elemental analysis and high-resolution mass spectrometry (HRMS) (see the SI). The ${ }^{1} \mathrm{H}$ NMR spectrum of 10 revealed the presence of signals at $5.38(\mathrm{I}=2), 4.72(\mathrm{I}=2)$ and $4.57(\mathrm{I}=4)$ ppm consistent with the acac $\mathrm{C}-\mathrm{H}$ resonances, and with the central and external quinoidal C-H protons, respectively (see the SI). At this stage, one can infer that formation of $\mathbf{1 0}$ results from an associative mechanism in which the incoming ligand 7 coordinates at the Ni center and assists the dissociation of the leaving acac ligand. 


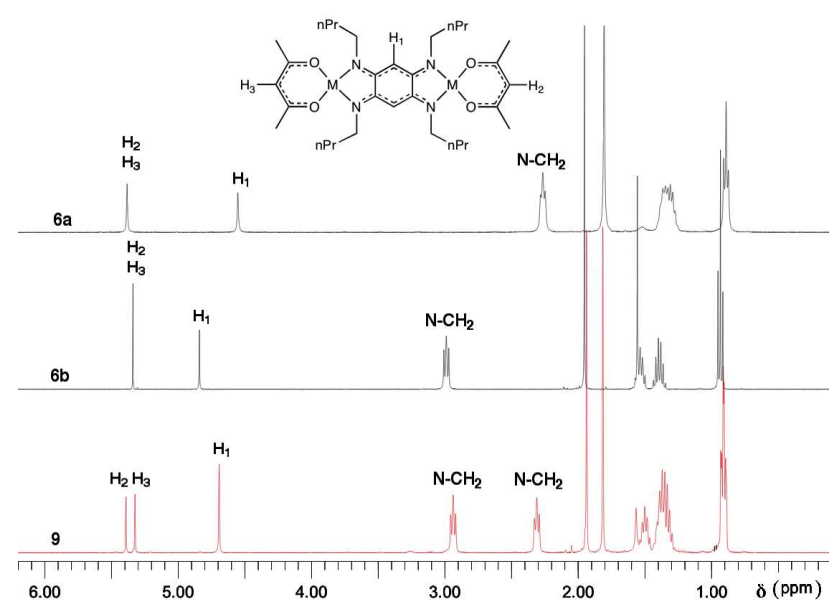

Figure 2. ${ }^{1} \mathrm{H}$ NMR spectra of $6 \mathrm{a}, 6 \mathrm{~b}$, and 9 in $\mathrm{CDCl}_{3}$.

DFT calculations have been carried out to provide further insights into the formation mechanism of $\mathbf{1 0}$ (see SI for details). These studies revealed that the process is not thermodynamically but kinetically controlled, and that the coordination at the nickel center of $\mathbf{9}$, either by surrounding solvent molecules (THF) or directly by 7 , leads to the formation of a favored octahedral intermediate in which the $\mathrm{O}-\mathrm{Ni}$ bond is weakened. NMR of 9 in THF- $\mathrm{d}_{8}$ clearly indicates the absence of high spin complex (i.e. no coordination of solvent). We have therefore evaluated the hypothesis of a directly attacking 7 on both the Ni and Pd centers of 9 and we found that the most stable 7+9 intermediate is constituted of a high-spin octahedral Ni environment (the most stable structure is displayed in Figure 3), whereas complexation on the Pd side offers structures higher in energy irrespective of the considered spin state. Therefore, the observed reactivity is probably due to the complexation of 7 , that allows this metal to go to the more reactive triplet state, in which breaking the acac bond is easier.

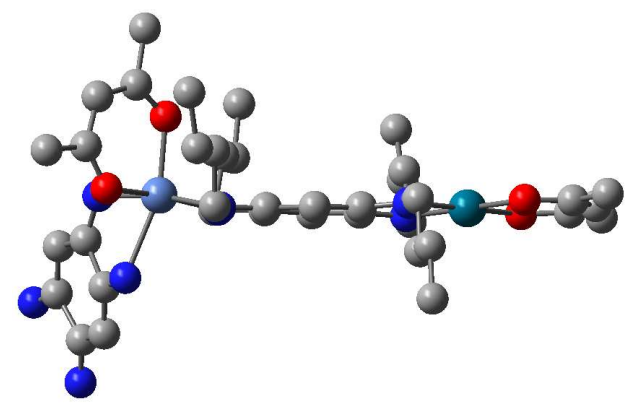

Figure 3. The most stable $7+9$ intermediate that could be obtained (triplet ground-state, complexation on the Ni side). The hydrogen atoms have been omitted for clarity.

The UV-Vis absorption spectra of 8 (Pd) and 9 (Ni-Pd) exhibit broad bands centered at 421 and $445 \mathrm{~nm}$ for 8 and 467 and 501 $\mathrm{nm}$ for 9 (Figure 4). As expected, complex $\mathbf{1 0}$ features a pronounced redshift and the absorption extends up to the far-red region as a result of the extension of the delocalization of the conjugated $\pi$-system. ${ }^{14}$ Remarkably, a considerable hyperchromic effect is also observed $\left(\varepsilon^{679 \mathrm{~nm}}=110400 \mathrm{M}^{-1} \mathrm{~cm}^{-1}\right.$ for $10 v s \varepsilon^{501 \mathrm{~nm}}=42400 \mathrm{M}^{-1} \mathrm{~cm}^{-1}$ for 9).

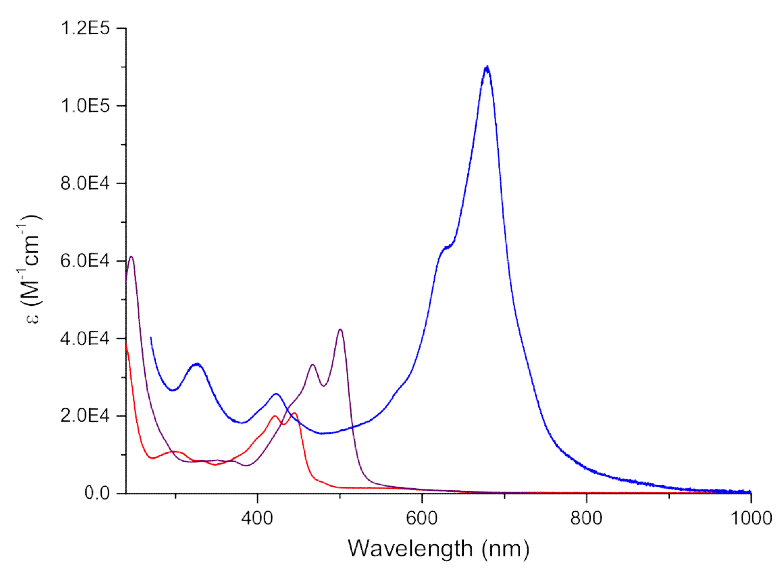


Figure 4. Absorption spectra of 8 (red), 9 (purple) and 10 (blue) in dichloromethane.

DFT calculations have also been carried out to establish relationships between the electronic spectrum and the $\pi$-electron delocalization in these compounds (see the SI for details). For 8, 9 and 10, TD-DFT returns the first significantly dipole-allowed excitedstates at $425 \mathrm{~nm}(f=0.34), 423 \mathrm{~nm}(f=1.03)$ and $517 \mathrm{~nm}(f=2.38)$ respectively. Obviously, the strong hyperchromic effect when going from the smallest to the largest compound is well reproduced by theory, e.g., the oscillator strength of $\mathbf{1 0}$ is 2.3 times larger than the one in $\mathbf{9}$, whereas the ratio between the measured $\varepsilon$ is 2.6. The bathochromic displacement when going from 9 to 10 , is also well captured by TD-DFT (exp: $-0.65 \mathrm{eV}$, theory: $-0.53 \mathrm{eV}$ ).

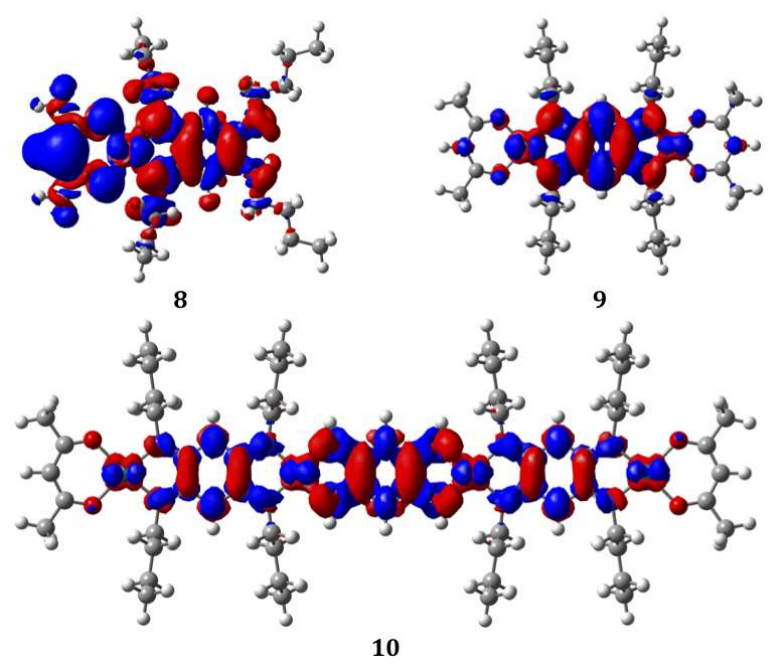

Figure 5. Density difference plots between the excited and ground states for 8,9 and 10 . Red (blue) regions indicate increase (decrease) of the density upon absorption. The selected contour threshold is 0.0004 au.

Nevertheless, we note that the computed wavelengths are too blueshifted, which is the logical consequence of neglecting vibronic effects, ${ }^{15}$ and the shift between $\mathbf{8}$ and $\mathbf{9}$ is not accurately restored by theory. The excited-states of these three compounds are analyzed as density difference plots in Figure 5. In 8, there is a strong charge-transfer from one side (mostly in blue) to the other of the molecule (mostly in red). In contrast, the density difference plots of $\mathbf{9}$ and $\mathbf{1 0}$ show highly-delocalized $\pi-\pi \square$ transitions which are strongly symmetric, involve the metallic centers, and present a nature alike the one obtained in homo-nuclear structures. ${ }^{14}$

\section{CONCLUSION}

In summary, we have reported a novel and straightforward route to access multinuclear complexes reaching the far-red region absorption. This approach is based on (i) a stepwise synthesis of a heterobinuclear Pd-Ni complex from a stable square planar mononuclear Pd(II) derivative, and (ii) an unprecedented heterobimetallic effect that allowed a selective concomitant ligand exchange. Soluble and stable hetero-tetranuclear complexes are now accessible for a wide range of technological sectors. As far-red absorbing organic materials, these new dyes are highly attractive in the optoelectronic field (OPV, DSSC, photodetection, conduction). ${ }^{16}$ As multinuclear complexes, they are also relevant for catalysis, ${ }^{17}$ and selective gas sensors thanks to the presence of two different metal centers able to bind an analyte (response by spin state changes in the case of nickel for instance). ${ }^{18}$

\section{EXPERIMENTAL SECTION}

Synthesis of 6a. To a solution of ligand $2(\mathrm{R}=\mathrm{nBu})(\mathrm{m}=144 \mathrm{mg}, 0.399 \mathrm{mmol}, 1$ equiv.) in THF $(\mathrm{v}=4 \mathrm{~mL})$ was added $\mathrm{Ni}(\mathrm{acac})_{2}(\mathrm{~m}=205 \mathrm{mg}, 0.798 \mathrm{mmol}, 2$ equiv.). The reaction mixture was stirred at room temperature overnight and the solvent was then removed under reduced pressure. The resulting solid was taken up in $\mathrm{Et}_{2} \mathrm{O}(\mathrm{v}=5 \mathrm{~mL})$ and the obtained precipitate was isolated by filtration, washed with $\mathrm{Et}_{2} \mathrm{O}(\mathrm{v}=3 \times 10 \mathrm{~mL})$ and dried under vacuum to afford $6 \mathbf{a}$ as a dark green crystalline powder $(\mathrm{m}=193$ $\mathrm{mg}, 0.286 \mathrm{mmol}, 72 \%$ yield). Monocrystal of 6a for X-ray analysis was obtained by slow diffusion with $\mathrm{CDCl}_{3} / n$-heptane. ${ }^{1} \mathrm{H}$ $\mathrm{NMR}\left(400 \mathrm{MHz}, \mathrm{CDCl}_{3}, 294 \mathrm{~K}\right): \delta(\mathrm{ppm})=5.38(\mathrm{~s}, 2 \mathrm{H}, \mathrm{CH}$-acac $), 4.55(\mathrm{~s}, 2 \mathrm{H}, \mathrm{N}-\mathrm{C}-\mathrm{C}-\mathrm{H}), 2.26\left(\mathrm{t},{ }^{3} J_{\mathrm{HH}}=7.0 \mathrm{~Hz}, 8 \mathrm{H}, \mathrm{N}-\mathrm{CH} \mathrm{H}^{-}\right), 1.80$ (s, $12 \mathrm{H}, \mathrm{CH}_{3}$-acac), 1.36-1.27 (m, $\left.16 \mathrm{H},-\mathrm{CH}_{2}-\mathrm{CH}_{2}-\mathrm{CH}_{3}\right), 0.89\left(\mathrm{t},{ }^{3} J_{\mathrm{HH}}=7.0 \mathrm{~Hz}, 12 \mathrm{H},-\mathrm{CH}_{2}-\mathrm{CH}_{3}\right) .{ }^{13} \mathrm{C} \mathrm{NMR}\left(100 \mathrm{MHz}^{3} \mathrm{CD}_{2} \mathrm{Cl}_{2}, 294\right.$ $\mathrm{K}): \delta(\mathrm{ppm})=187.2,166.0,101.6,84.2,43.8,31.4,25.8,21.1,14.3$. HRMS (ESI-TOF): $\mathrm{m} / \mathrm{z}[\mathrm{M}+\mathrm{H}]^{+}$for $\mathrm{C}_{32} \mathrm{H}_{53} \mathrm{~N}_{4} \mathrm{O}_{4} \mathrm{Ni}_{2}{ }^{+}$calcd. 673.2768, found 673.2767, err. $<1$ ppm. Elemental analysis for $\mathrm{C}_{32} \mathrm{H}_{52} \mathrm{~N}_{4} \mathrm{O}_{4} \mathrm{Ni}_{2}$ (674.17): calcd. C 57.01, $\mathrm{H} \mathrm{7.77,} \mathrm{N} \mathrm{8.31} \mathrm{found} \mathrm{C}$ 56.94, H 7.84, N 8.18.

Synthesis of $\mathbf{6 b}$. To a solution of ligand $2(\mathrm{R}=\mathrm{nBu})(\mathrm{m}=50 \mathrm{mg}, 0.139 \mathrm{mmol}, 1$ equiv. $)$ in 1,4-dioxane $(\mathrm{v}=3 \mathrm{~mL})$ was added $\operatorname{Pd}(\mathrm{acac})_{2}(\mathrm{~m}=85 \mathrm{mg}, 0.279 \mathrm{mmol}, 2$ equiv. $)$. The reaction mixture was heated overnight at $100{ }^{\circ} \mathrm{C}$. The solvent was then removed 
under reduced pressure and the resulting solid was washed with $\mathrm{Et}_{2} \mathrm{O}(\mathrm{v}=3 \times 3 \mathrm{~mL})$, isolated by filtration and dried under vacuum to afford $\mathbf{6 b}$ as a brown crystalline powder $(\mathrm{m}=74 \mathrm{mg}, 0.096 \mathrm{mmol}, 70 \%$ yield). Monocrystal of $\mathbf{6 b}$ for X-ray analysis was obtained by slow diffusion with $\mathrm{CDCl}_{3} / n$-heptane. ${ }^{1} \mathrm{H} \mathrm{NMR}\left(400 \mathrm{MHz}, \mathrm{CDCl}_{3}\right) \delta(\mathrm{ppm})=5.33(\mathrm{~s}, 2 \mathrm{H}, \mathrm{CH}$-acac), $4.83(\mathrm{~s}, 2 \mathrm{H}, \mathrm{N}-\mathrm{C}-\mathrm{C}-$ $H), 2.98\left(\mathrm{t},{ }^{3} J_{\mathrm{HH}}=7.2 \mathrm{~Hz}, 8 \mathrm{H}, \mathrm{N}-\mathrm{CH}_{2}-\right), 1.94\left(\mathrm{~s}, 12 \mathrm{H}, \mathrm{CH}_{3}-\mathrm{acac}\right), 1.56-1.49\left(\mathrm{~m}, 8 \mathrm{H}, \mathrm{N}-\mathrm{CH}_{2}-\mathrm{CH}_{2}-\right), 1.43-1.34\left(\mathrm{~m}, 8 \mathrm{H},-\mathrm{CH}_{2}-\mathrm{CH}_{3}\right)$, $0.93\left(\mathrm{t},{ }^{3} J_{\mathrm{HH}}=7.3 \mathrm{~Hz}, 12 \mathrm{H},-\mathrm{CH}_{2}-\mathrm{CH}_{3}\right) .{ }^{13} \mathrm{C} \mathrm{NMR}\left(400 \mathrm{MHz}, \mathrm{CDCl}_{3}\right) \delta(\mathrm{ppm})=186.3,167.7,101.0,82.6,46.8,30.6,26.5,20.6$, 14.1. MS (ESI-TOF): $\mathrm{m} / \mathrm{z}[\mathrm{M}+\mathrm{H}]^{+}$for $\mathrm{C}_{32} \mathrm{H}_{53} \mathrm{~N}_{4} \mathrm{O}_{4} \mathrm{Pd}_{2}^{+}$calcd. 771.2, found 771.2. Elemental analysis for $\mathrm{C}_{32} \mathrm{H}_{52} \mathrm{~N}_{4} \mathrm{O}_{4} \mathrm{Pd}_{2}(769.62)$ : calcd. C 49.94, H 6.81, N 7.28 found C 49.89, H 6.63, N 7.13. UV-Vis Absorption in $\mathrm{CH}_{2} \mathrm{Cl}_{2}: \varepsilon^{481 \mathrm{~nm}}=60000 \mathrm{M}^{-1} \mathrm{~cm}^{-1}, \varepsilon^{450 \mathrm{~nm}^{2}}=33$ $200 \mathrm{M}^{-1} \mathrm{~cm}^{-1}, \varepsilon^{423 \mathrm{~nm}}=15700 \mathrm{M}^{-1} \mathrm{~cm}^{-1}, \varepsilon^{338 \mathrm{~nm}}=5900 \mathrm{M}^{-1} \mathrm{~cm}^{-1}$.

Synthesis of 8 . To a solution of ligand $2(\mathrm{R}=\mathrm{nBu})(\mathrm{m}=180 \mathrm{mg}, 0.499 \mathrm{mmol}, 1$ equiv. $)$ in 1,4-dioxane $(\mathrm{v}=25 \mathrm{~mL})$, were added $\operatorname{Pd}(\mathrm{acac})_{2}(\mathrm{~m}=152 \mathrm{mg}, 0.499 \mathrm{mmol}, 1$ equiv. $)$ and aq. $\mathrm{HBF}_{4}(0.153 \mathrm{M}, \mathrm{v}=3.26 \mathrm{~mL}, 0.499 \mathrm{mmol}, 1$ equiv. $)$. The mixture was stirred at reflux under argon for $7 \mathrm{~h}$. The solvent was then removed under reduced pressure and the residue was taken up in $\mathrm{Et}_{2} \mathrm{O} / \mathrm{CH}_{2} \mathrm{Cl}_{2}$ and sonicated. The obtained precipitate was isolated by filtration, washed with $\mathrm{Et}_{2} \mathrm{O}(\mathrm{v}=2 \times 50 \mathrm{~mL})$ and dried under vacuum to afford $\mathbf{8}$ as a dark brown powder ( $\mathrm{m}=284 \mathrm{mg}, 0.435 \mathrm{mmol}, 81 \%$ yield). Molecule $\mathbf{8}$ is stable in solution under air and moisture. Monocrystal of 8 for X-ray analysis was obtained by slow diffusion with $\mathrm{CH}_{2} \mathrm{Cl}_{2} / \mathrm{n}$-heptane. ${ }^{1} \mathrm{H} \mathrm{NMR}(400 \mathrm{MHz}$, $\mathrm{CDCl}_{3}, 294 \mathrm{~K}$ ): $\delta=6.86$ (br t, $\left.2 \mathrm{H}, \mathrm{NH}\right), 5.48\left(\mathrm{~s}, 1 \mathrm{H}, \mathrm{CH}\right.$-acac), 5.24 (s, 2H, N-C-C-H), 3.30-3.21 (m, 8H, $\left.-\mathrm{CH}_{2}-\mathrm{CH}_{2}-\mathrm{CH}_{3}\right), 2.06(\mathrm{~s}$, $6 \mathrm{H}, \mathrm{CH}_{3}$-acac), 1.74 (quintet, ${ }^{3} J_{\mathrm{HH}}=7.5 \mathrm{~Hz}, 4 \mathrm{H}, \mathrm{NH}-\mathrm{CH}_{2}-\mathrm{CH}_{2}$ ), 1.61 (quintet, $\left.{ }^{3} J_{\mathrm{HH}}=7.5 \mathrm{~Hz}, 4 \mathrm{H}, \mathrm{N}-\mathrm{CH}_{2}-\mathrm{CH}_{2}-\right), 1.48-1.37(\mathrm{~m}, 8 \mathrm{H}$, $\left.-\mathrm{CH}_{2}-\mathrm{CH}_{3}\right), 0.99-0.94\left(\mathrm{~m}, 12 \mathrm{H},-\mathrm{CH}_{2}-\mathrm{CH}_{3}\right) .{ }^{13} \mathrm{C} \mathrm{NMR}\left(100 \mathrm{MHz}, \mathrm{CDCl}_{3}, 294 \mathrm{~K}\right): \delta=186.9,167.5,148.7,101.8,86.3,48.4,44.1$, 31.1, 29.2, 26.3, 20.6, 20.3, 14.0, 13.7. ${ }^{19} \mathrm{~F}$ NMR (376 MHz, $\left.\mathrm{CDCl}_{3}, 294 \mathrm{~K}\right): \delta=-150.42,-150.47 . \mathrm{HRMS}(\mathrm{ESI}-\mathrm{TOF}): \mathrm{m} / \mathrm{z} \mathrm{M}^{+}$for $\mathrm{C}_{27} \mathrm{H}_{47} \mathrm{~N}_{4} \mathrm{O}_{2} \mathrm{Pd}^{+}$calcd. 565.2739, found 565.2740, err. $<1 \mathrm{ppm}$. Elemental analysis for $\mathrm{C}_{27} \mathrm{H}_{47} \mathrm{BF}_{4} \mathrm{~N}_{4} \mathrm{O}_{2} \mathrm{Pd}^{1}{ }^{1} / 6 \mathrm{CH}_{2} \mathrm{Cl}_{2}(667.07)$ : calcd. $\mathrm{C} 48.91, \mathrm{H} 7.15, \mathrm{~N} 8.40$; found C 48.71, H 6.66, N 8.89. UV-Vis Absorption in $\mathrm{CH}_{2} \mathrm{Cl}_{2}: \varepsilon^{445 \mathrm{~mm}}=20900 \mathrm{M}^{-1} \mathrm{~cm}^{-1}, \varepsilon^{421 \mathrm{~nm}}=20100 \mathrm{M}^{-}$ ${ }^{1} \mathrm{~cm}^{-1}, \varepsilon^{332 \mathrm{~nm}}=8600 \mathrm{M}^{-1} \mathrm{~cm}^{-1}, \varepsilon^{298 \mathrm{~nm}}=10900 \mathrm{M}^{-1} \mathrm{~cm}^{-1}$.

Synthesis of 9. To a solution of $8(\mathrm{~m}=50 \mathrm{mg}, 76.6 \mu \mathrm{mol}, 1$ equiv. $)$ in $\mathrm{MeOH}(\mathrm{v}=6 \mathrm{~mL})$, was added $\mathrm{Ni}(\mathrm{acac}) 2(\mathrm{~m}=62 \mathrm{mg}, 241$ $\mu \mathrm{mol}, 3.15$ equiv.). The reaction was stirred at $60^{\circ} \mathrm{C}$ overnight. The resulting precipitate was isolated by a filtration, washed with $\mathrm{MeOH}$ and $\mathrm{EtOH}$, dried under vacuum to afford the desired product 9 as a brown powder $(\mathrm{m}=20 \mathrm{mg}, 27.7 \mu \mathrm{mol}, 37 \%$ yield). Molecule 9 is stable in solution under air and moisture. Monocrystal of $\mathbf{9}$ for X-ray analysis was obtained by slow diffusion with $\mathrm{CH}_{2} \mathrm{Cl}_{2} / \mathrm{MeOH} .{ }^{1} \mathrm{H}$ NMR $\left(400 \mathrm{MHz}, \mathrm{CDCl}_{3}, 298 \mathrm{~K}\right): \delta=5.39$ (s, $1 \mathrm{H}, \mathrm{CH}$-acacNi), 5.32 (s, 1H, CH-acacPd), 4.69 (s, 2H, N-C-C$H), 2.94\left(\mathrm{t},{ }^{3} J_{\mathrm{HH}}=7.3 \mathrm{~Hz}, 4 \mathrm{H}, \mathrm{Pd}-\mathrm{N}-\mathrm{CH}_{2}-\right), 2.31\left(\mathrm{t},{ }^{3} J_{\mathrm{HH}}=7.2 \mathrm{~Hz}, 4 \mathrm{H}, \mathrm{Ni}-\mathrm{N}-\mathrm{CH}_{2}-\right), 1.94\left(\mathrm{~s}, 6 \mathrm{H}, \mathrm{CH}_{3}\right.$-acacPd $), 1.81\left(\mathrm{~s}, 6 \mathrm{H}, \mathrm{CH} 3^{-}\right.$ acacNi), $1.54-1.46\left(\mathrm{~m}, 4 \mathrm{H}, \mathrm{Pd}-\mathrm{N}-\mathrm{CH}_{2}-\mathrm{CH}_{2}-\right), 1.43-1.28\left(\mathrm{~m}, 12 \mathrm{H},-\mathrm{CH}_{2}-\right), 0.93-0.89\left(\mathrm{~m}, 12 \mathrm{H},-\mathrm{CH}_{3}\right) .{ }^{13} \mathrm{C} \mathrm{NMR}\left(100 \mathrm{MHz}, \mathrm{CDCl}{ }_{3}\right.$, $294 \mathrm{~K}): \delta=186.5,186.3,167.9,165.5,101.4,100.9,83.3,46.8,43.5,31.0,30.5,26.5,25.6,20.8,20.6,14.1$, 14.1. HRMS (ESITOF): $\mathrm{m} / \mathrm{z}[\mathrm{M}+\mathrm{H}]^{+}$for $\mathrm{C}_{32} \mathrm{H}_{53} \mathrm{~N}_{4} \mathrm{O}_{4} \mathrm{NiPd}$ calcd. 723.2444 , found 723.2445 , err. $<1$ ppm. Elemental analysis for $\mathrm{C}_{32} \mathrm{H}_{52} \mathrm{~N}_{4} \mathrm{NiO}_{4} \mathrm{Pd} \cdot \mathrm{H}_{2} \mathrm{O}$ (739.91): calcd. C 51.94, H 7.35, N 7.57; found C 52.20, H 7.12, N 7.61. UV-Vis Absorption in $\mathrm{CH}_{2} \mathrm{Cl}_{2}: \varepsilon^{501}$ $\mathrm{nm}=42400 \mathrm{M}^{-1} \mathrm{~cm}^{-1}, \varepsilon^{467 \mathrm{~nm}}=33400 \mathrm{M}^{-1} \mathrm{~cm}^{-1}, \varepsilon^{368 \mathrm{~nm}}=8500 \mathrm{M}^{-1} \mathrm{~cm}^{-1}, \varepsilon^{351 \mathrm{~nm}}=8700 \mathrm{M}^{-1} \mathrm{~cm}^{-1}, \varepsilon^{246 \mathrm{~nm}}=61300 \mathrm{M}^{-1} \mathrm{~cm}^{-1}$.

Synthesis of 10. To a solution of $9(\mathrm{~m}=60 \mathrm{mg}, 83.1 \mu \mathrm{mol}, 1.9$ equiv.) in THF ( $\mathrm{v}=5 \mathrm{~mL})$, were added $7(\mathrm{~m}=5.9 \mathrm{mg}, 43.3 \mu \mathrm{mol}, 1$ equiv.) and 2 drops of $i \operatorname{Pr}_{2} \mathrm{NEt}$. The mixture was stirred at room temperature for 3 days. The resulting precipitate was isolated by a filtration and taken up in $\mathrm{CH}_{2} \mathrm{Cl}_{2}$. The unsoluble solid was then filtered off and the filtrate was evaporated under vacuum to afford a crude product. This latter was washed with acetone (containing $1 \% \mathrm{Et}_{3} \mathrm{~N}$ ), $\mathrm{Et}_{2} \mathrm{O}$, and dried under vacuum to afford $\mathbf{1 0}$ as a dark blue powder $\left(\mathrm{m}=26 \mathrm{mg}, 18.8 \mu \mathrm{mol}, 46 \%\right.$ yield). ${ }^{1} \mathrm{H}$ NMR $\left(400 \mathrm{MHz}, \mathrm{CDCl}_{3}, 294 \mathrm{~K}\right): \delta=5.33(\mathrm{~s}, 2 \mathrm{H}, \mathrm{CH}$-acacPd), 4.73 (s, 2H, NH-CC-H), 4.71 (s, 4H, N-C-C-H), 3.55 (br s, 4H, NH), 2.95 (br t, 8H, Pd-N-CH $2^{-}$), 2.60 (br t, 8H, Ni-N-CH $2_{2}$ ), 1.94 (s, $12 \mathrm{H}, \mathrm{CH}_{3^{-}}$ acacPd), $1.52-1.43\left(\mathrm{~m}, 8 \mathrm{H}, \mathrm{Pd}-\mathrm{N}-\mathrm{CH}_{2}-\mathrm{CH}_{2}-\right), 1.40-1.29\left(\mathrm{~m}, 24 \mathrm{H},-\mathrm{CH}_{2}-\right), 0.95-0.89\left(\mathrm{~m}, 24 \mathrm{H},-\mathrm{CH}_{3}\right)$. No ${ }^{13} \mathrm{C}$ NMR spectrum of 10 could be recorded owing to its poor solubility. HRMS (ESI-TOF): $\mathrm{m} / \mathrm{z}[\mathrm{M}+\mathrm{H}]^{+}$for $\mathrm{C}_{60} \mathrm{H}_{97} \mathrm{~N}_{12} \mathrm{O}_{4} \mathrm{Ni}_{2} \mathrm{Pd}_{2}{ }^{+}$, calcd. 1379.4533, found 1379.4535, error $<2$ ppm. Elemental analysis for $\mathrm{C}_{60} \mathrm{H}_{96} \mathrm{~N}_{12} \mathrm{Ni}_{2} \mathrm{O}_{4} \mathrm{Pd}_{2} \cdot \mathrm{CH}_{2} \mathrm{Cl}_{2}$ (1464.64): calcd. C 50.02, $\mathrm{H}$ 6.74, $\mathrm{N} 11.48$; found C 49.60, H 6.52, N 11.93. UV-Vis Absorption in $\mathrm{CH}_{2} \mathrm{Cl}_{2}$ containing $0.5 \%$ of DIPEA: $\varepsilon^{679 \mathrm{~nm}}=110400 \mathrm{M}^{-1} \mathrm{~cm}^{-1}, \varepsilon^{628 \mathrm{~nm}}=64900 \mathrm{M}^{-}$ ${ }^{1} \mathrm{~cm}^{-1}, \varepsilon^{422 \mathrm{~nm}}=28000 \mathrm{M}^{-1} \mathrm{~cm}^{-1}, \varepsilon^{325 \mathrm{~nm}}=35500 \mathrm{M}^{-1} \mathrm{~cm}^{-1}$.

\section{ASSOCIATED CONTENT}

${ }^{1} \mathrm{H}$ and ${ }^{13} \mathrm{C}$ NMR spectra, theoretical calculations details, electrochemistry and mass spectrometry data. X-ray crystallographic data for $\mathbf{6 a}$, 6b and 9.

\section{AUTHOR INFORMATION}

\section{Corresponding Authors}

*D.J.: Denis.Jacquemin@univ-nantes.fr

*O.S.: olivier.siri@univ-amu.fr

\section{ORCID}

Christophe Bucher: 0000-0003-1803-6733

Gabriel Canard: 0000-0002-3572-9091

Michel Giorgi: 0000-0002-4367-1985

Denis Jacquemin: 0000-0002-4217-0708 


\section{ACKNOWLEDGMENT}

OS acknowledges the Centre National de la Recherche Scientifique, the Ministère de la Recherche for financial support and PhD grant to ZC. OS and DJ thank the ANR for support (EMA grant). This research used resources of (1) the GENCI-CINES/IDRIS, (2) CCIPL (Centre de Calcul Intensif des Pays de Loire), (3) the local Troy cluster acquired thanks to Région des Pays de la Loire.

\section{REFERENCES}

(1) a) Brown, E. R. Quinonediimines, monoimines and related compounds, in The Quinonoid Compounds (1988), John Wiley \& Sons Inc, 2010, pp. 1231-1292. b) Hünig, S. Aromatic/quinoid systems: principles and applications Pure Appl. Chem. 1990, 62 395. c) Moussa, J.; Amouri, H. Supramolecular Assemblies Based on Organometallic Quinonoid Linkers: A New Class of Coordination Networks Angew. Chem. Int. Ed. 2008, 47, 1372. d) Casado, J.; Ponce Ortiz, R.; Lopez Navarrete, J. T. Quinoidal oligothiophenes: new properties behind an unconventional electronic structure Chem. Soc. Rev. 2012, 41, 5672. e) Asche, C. Med. Chem. 2005, 5, 449. f) López, J.; de la Cruz, F.; Alcaraz, Y.; Delgado, F.; Vázquez, M. A. Quinoid systems in chemistry and pharmacology Med. Chem. Res. 2015, 24, 3599. g) Ward, M. D. Metal-metal interactions in binuclear complexes exhibiting mixed valency; molecular wires and switches Chem. Soc. Rev. 1995, 24, 121. h) Demir, S.; Jeon, I.-R.; Long, J. R.; Harris, Radical ligand-containing single-molecule magnets T. D. Coord. Chem. Rev. 2015, 289-290, 149. i) Sarkar, B.; Schweinfurth, D.; Deibel, N.; Weisser, F. Functional metal complexes based on bridging "imino"-quinonoidligands Coord. Chem. Rev. 2015, 293-294, 250.

(2) a) Masui, H.; Lever, A. B. P. Correlations between the ligand electrochemical parameter, EL(L), and the Hammett substituent parameter, sigma. Inorg. Chem. 1993, 32, 2199. b) Metcalfe, R. A.; Vasconcellos, L. C. G. ; Mirza, H. ; Franco, D. W. ; Lever, A. B. P. Synthesis and characterization of dinuclear complexes of 3,3',4,4'-tetraminobiphenyl with tetramminoruthenium and bis(bipyridine)-ruthenium residues and their twoand four-electron oxidized products including a ZINDO study of orbital mixing as a function of ligand oxidation state J. Chem. Soc., Dalton Trans. 1999, 2653

(3) Pascal, S.; Siri O. Benzoquinonediimine ligands: Synthesis, coordination chemistry and properties Coord. Chem. Rev. 2017, $350,178$.

(4) Kitagawa, S.; Kawata, S. Coordination compounds of 1,4-dihydroxybenzoquinone and its homologues. Structures and properties Coord. Chem. Rev. 2002, 224, 11.

(5) a) Kimich, C. Einwirkung aromatischer Amine auf Nitrosophenol und Nitrosodimethylanilin Chem. Ber. 1875, 8, 1026. b) Fischer, O.; Hepp, E. Ueber Azophenin und Chinonanilide. II Chem. Ber. 1888, 21, 676. c) Bandrowski, E.V. Über die Oxydation des Paraphenylendiamins und des Paraamidophenols Monatsh. Chem. 1889, 10, 123. d) Siri, O.; Braunstein, P. First binuclear complex of an N,N',N",N"'-tetraalkyl 2,5-diamino-1,4benzoquinonediimine Chem. Commun. 2000, 2223. e) Siri, O.; Braunstein, P.; Rohmer, M.-M.; Bénard, M.; Welter, R. Novel "Potentially Antiaromatic", Acidichromic Quinonediimines with Tunable Delocalization of Their 6 $\pi$-Electron Subunits J. Am. Chem. Soc. 2003, 125 13793. f) Seillan, C.; Braunstein, P.; Siri, O. Selective Reduction of Carbonyl Amides: Toward the First Unsymmetrical Bischelating N-Substituted 1,2-Diamino-4,5-di-amidobenzene Eur. J. Org. Chem. 2008, 3113. g) Wenderski, T.; Light, K. M.; Ogrin, D.; Bott, S. G.; Harlan, C. J. Pd catalyzed coupling of 1,2-dibromoarenes and anilines: formation of N,N-diaryl-o-phenylenediamines Tetrahedron Lett. 2004, 45, 6851. h) Khramov, D. M.; Boydston, A. J.; Bielawski, C. W. ighly Efficient Synthesis and Solid-State Characterization of 1,2,4,5-Tetrakis(alkyl- and arylamino)benzenes and Cyclization to Their Respective Benzobis(imidazolium) Salts Org. Lett. 2006, 8, 1831. i) Ohno, K.; Nagasawa, A.; Fujihara, T. Dinuclear nickel(II) complexes with 2,5-diamino-1,4-benzoquinonediimine ligands as precatalysts for the polymerization of styrene: electronic and steric substituent effects Dalton Trans. 2015, 44, 368. j) Abdelhameed, M.; Langlois, A.; Fortin, D.; Karsenti, P.-L.; Harvey, P. D. A drastic substituent effect on the emission properties of quinone diimine models and valuable insight into the excited states of emeraldine Chem. Commun. 2014, 50, 11214. k) Andeme Edzang, J.; Chen, Z.; Audi, H.; Canard, G.; Siri, O. Transamination at the Crossroad of the One-Pot Synthesis of N-Substituted Quinonediimines and C-Substituted Benzobisimidazoles Org. Lett. 2016, $18,5340$.

(6) a) Rall, J.; Stange, A. F.; Hübler, K.; Kaim, W. A Coordination-Induced 1,4 $\rightarrow 1,2$-Quinonediimine Isomerization Angew. Chem. Int. Ed. 1998, 37, 2681. b) Frantz, S.; Rall, J.; Hartenbach, I.; Schleid, T.; Záliš, S.; Kaim, Metal-Induced Tautomerization of p- to o-Quinone Compounds: Experimental Evidence from CuI and ReI Complexes of Azophenine and DFT Studies W. Chem. Eur. J. 2004, 10, 149. c) Braunstein, P.; Demessence, A.; Siri, O.; Taquet, J.-P. Relocalisation of the $\pi$ system in benzoquinonediimines induced by metal coordination C. R. Chim. 2004, 7, 909.

(7) a) Cheng, H.-Y.; Lee, G.-H.; Peng, S.-M. Coordination chemistry of sulfonyl amides 3. Copper(I) and nickel(II) complexes of N, N',N", $\mathrm{N}^{\prime \prime \prime}-$ tetramethylsulfonyl-1,4-benzoquinonediimine-2,5-diaminato Inorg. Chim. Acta 1992, 191, 25-27. b) Trumm, C.; Hübner, O.; Kaifer, E.; Himmel, H.-J. Trapped in a Complex: the 1,2,4,5-Tetrakis(tetramethylguanidino)benzene Radical Cation $(\mathrm{ttmgb+ \cdot})$ with a Bisallylic Structure Eur. J. Inorg. Chem. 2010, 3102. c) Jeon, I.-R.; Park, J. G.; Xiao, D. J.; Harris, T. D. An Azophenine Radical-Bridged Fe2 Single-Molecule Magnet with Record Magnetic Exchange Coupling J. Am. Chem. Soc. 2013, 135, 16845. d) DeGayner, J. A. ; Jeon, I.-R. ; Harris, T. D. A series of tetraazalene radicalbridged M2 (M = CrIII, MnII, FeII, CoII) complexes with strong magnetic exchange coupling Chem. Sci. 2015, 6, 6639.

(8) a) Taquet, J.-P.; Siri, O.; Braunstein, P.; Welter, R. Dinuclear Nickel and Palladium Complexes with Bridging 2,5-Diamino-1,4benzoquinonediimines: Synthesis, Structures, and Catalytic Oligomerization of Ethylene Inorg. Chem. 2006, 45, 4668. b) Huang, Y.-B.; Tang, G.R.; Jin, G.-Y.; Jin, G.-X. Novel, Highly Active Binuclear 2,5-Disubstituted Amino-p-benzoquinone-Nickel(II) Ethylene Polymerization Catalysts Organometallics 2008, 27, 259. c) Siri, O.; Taquet, J.-p.; Braunstein, P.; Collin, J.-P.; Rohmer M.-M.; Bénard, M. Tunable Charge Delocalization in Dinickel Quinonoid Complexes Chem. Eur. J. 2005, 11, 7247.

(9) Su, Y.; Zhao, Y.; Gao, J.; Dong, Q.; Wu, B.; Yang, X.-J. Alkali Metal and Zinc Complexes of a Bridging 2,5-Diamino-1,4Benzoquinonediimine Ligand Inorg. Chem. 2012, 51, 5889.

(10) a) Schweinfurth, D.; Khusniyarov, M. M.; Bubrin, D.; Hohloch, S.; Su, C.-Y.; Sarkar, B. Tuning Spin-Spin Coupling in Quinonoid-Bridged Dicopper(II) Complexes through Rational Bridge Variation Inorg. Chem. 2013, 52, 10332. b) Deibel, N.; Sommer, M. G.; Hohloch, S.; Schwann, J.; Schweinfurth, D.; Ehret, F.; Sarkar, B. Dinuclear Quinonoid-Bridged d8 Metal Complexes with Redox-Active Azobenzene Stoppers: Electrochemical Properties and Electrochromic Behavior Organometallics 2014, 33, 4756.

(11) Ohno, K.; Fujihara, T.; Nagasawa, A. Formation of boron, nickel(II) and iridium(III) complexes with an azophenine derivative: Isomerization, delocalization and extension of the $\pi$-conjugated system on coordination Polyhedron 2014, 81, 715.

(12) a) Basolo, F. ; Pearson, R. G. Mechanisms of Inorganic Chemistry, 2nd edn, Wiley, New York, 1967; b) Wilkins, R. G. The Study of Kinetics and Mechanism of Reactions of Transition Metal Complexes, Allyn Bacon, Boston 1974 chapt.7.

(13) a) Porterfield, W. W. Inorganic Chemistry, Addison-Wesley, Reading, MA, 1983, pp. 561-575; b) Langford, C. H. ; Gray, H. B. Ligand Substitution Processes, W.A. Benjamin, New York, 1966; c) Jordan, R. B. Reaction Mechanisms of Inorganic and Organometallic Systems, 2nd 
edn, Oxford University Press, New York, 1998, p. 116; d) Sykes, A. G. Kinetics of Inorganic Reactions, Pergamon Press, New York, 1966, pp. 250-261.

(14) Audi, H.; Chen, Z.; Charaf-Eddin, A.; D’Aleo, A.; Canard, G.; Jacquemin, D.; Siri, O. Extendable nickel complex tapes that reach NIR absorptions Chem. Commun. 2014, 50, 15140.

(15) Santoro, S. ; Jacquemin D. Going beyond the vertical approximation with time-dependent density functional theory WIREs Comput Mol Sci 2016, 6, 460.

(16) Qian, G. ; Wang, Z. Y. Near-Infrared Organic Compounds and Emerging Applications Chem. - Asian J. 2010, 5, 1006.

(17) a) Moriuchi, T.; Hirao, T. Design and Redox Function of Conjugated Complexes with Polyanilines or Quinonediimines Acc. Chem. Res. 2012, 45, 347. b) Ishii, Y.; Sakaguchi, S.; Iwahama, T. Innovation of Hydrocarbon Oxidation with Molecular Oxygen and Related Reactions $A d v$. Synth. Catal. 2001, 343, 393. c) Ward M. D.; McCleverty, J. A. Non-innocent behaviour in mononuclear and polynuclear complexes: consequences for redox and electronic spectroscopic properties J. Chem. Soc., Dalton Trans., 2002, 275. d) Bäckvall, J.-E. Modern Oxidation Methods, WileyVCH, Weinheim, Germany, 2004. e) Holliday B. J.; Swager, T. M. Conducting metallopolymers: the roles of molecular architecture and redox matching Chem. Commun. 2005, 23. f) Nishihara, H. Combination of redox- and photochemistry of azo-conjugated metal complexes Coord. Chem. Rev., 2005, 249, 1468. g) Wolf, M. O. Recent Advances in Conjugated Transition Metal-containing Polymers and Materials J. Inorg. Organomet. Polym. Mater., 2006, 16, 189.

(18) Kar, P.; Yoshida, M.; Shigeta, Y.; Usui, A.; Kobayashi, A.; Minamidate, T.; Matsunaga, N.; Kato, M. Methanol-Triggered Vapochromism Coupled with Solid-State Spin Switching in a Nickel(II)-Quinonoid Complex Angew. Chem. Int. Ed. 2017, 56, 2345. 